\title{
ACOLHIMENTO, PROTEÇÃO E INSERÇÃO: UMA REFLEXÃO SOBRE A METODOLOGIA DO PROJETO DE APOIO A REFUGIADOS EM RORAIMA (2017-2018)
}

\author{
José CARlos Franco de Lima ${ }^{1}$ \\ ORCID 0000-0003-3114-1618
}

\begin{abstract}
Resumo: Este artigo apresenta os princípios metodológicos das ações de extensão voltadas para migrantes do Instituto de Antropologia da Universidade Federal de Roraima (UFRR) no período de 2017-2018. A metodologia usada no projeto se inspira na Investigacion Accion Participativa, por nós denominada Pesquisa Ação Participante. O objetivo principal do projeto foi desenvolver ações de acolhimento, apoio, proteção e inserção dos migrantes em Roraima, sejam eles refugiados ou residentes temporários. Trabalhamos na perspectiva de construir redes de cooperação envolvendo a UFRR, organizações não-governamentais e voluntariados voltadas ao acolhimento, apoio, proteção e inserção dos imigrantes em Roraima. Iniciamos o projeto com as seguintes ações: ofertas de aulas de português no Centro de Referência dos Imigrantes, Recanto Apuí e Núcleo de Pesquisa em Relações Internacionais; realização de documentários e pesquisas sociais com fins de sensibilizar a opinião pública para o acolhimento e subsidiar ações governamentais, não-governamentais e a auto organização dos migrantes; divulgação do projeto junto à imprensa e às redes sociais para informar os interessados e sensibilizar a opinião pública para o acolhimento aos migrantes; realização de atividades lúdicas, recreativas e educativas, em especial, junto às crianças e mães abrigadas no Centro de Referência dos Imigrantes do Bairro Pintolândia; promoção de campanhas de doação de roupas e alimentos; orientação jurídica aos migrantes na UFRR; participação em reuniões ampliadas de entidades públicas e privadas que desenvolvem ações junto aos refugiados e participação em seminários sobre a situação dos refugiados em Roraima. Em 2018, nos concentramos na parceria com a Associação Cultural Locombia Teatro de Andanças (ASCALTA) no desenvolvimento do Projeto Apuí, cujo escopo é a constituição de dois espaços para abrigamento e desenvolvimento de ações culturais.
\end{abstract}

1 Pós-doutorado em psicologia social pela UNESP, doutor em antropologia pela PUC/SP, mestre em sociologia política PUC/SP, especialista em antropologia filosófica pela UFPR, diretor do Instituto de Antropologia (INAN) da Universidade Federal de Roraima (UFRR), coordenador do Projeto de Apoio aos Refugiados em Roraima INAN/UFRR. 
Palavras-chave: MIGRAÇÃO VENEZUELANA. PESQUISA AÇÃO PARTICIPANTE. ANTROPOLOGIA DAS MIGRAÇÕES. MOVIMENTOS SOCIAIS

Abstract: This article presents the methodological principles of the migrant outreach programs at the Federal University of Roraima's (UFRR) Institute of Anthropology from 2017 to 2018. The methodology used in the project is inspired by the Investigacion Accion Participativa, also known as the Participative Investigation Action. The principal objective of the project was to develop projects related to receiving, supporting, protecting and integrating of immigrants in Roraima, whether they are refugees or temporary residents. We work from the perspective of building networks of cooperation involving the UFRR, non-governmental organizations and volunteers focused on receiving, supporting, protecting, and integrating of immigrants in Roraima. We began our initiative with the following programs: offering Portuguese classes at the Reference Center for Immigrants, Recanto Apuí and the Nucleus of Research in International Relations; the presentation of documentaries and social research with hopes to improve the public opinion of those arriving and subsidize governmental, nongovernmental and self-organization projects for migrants; dissemination of the project to the press and social networks to inform those interested as well as to raise public awareness of the arrival of migrants; providing fun recreational and educational activities, especially involving the children and mothers of the Reference Center for Immigrants living in the Pintolândia neighborhood; promotion of food and clothing drives; legal guidance for the migrants at UFRR; participation in meetings with public and private entities involved in the development of refugee programs and participation in seminars on the refugee situation in Roraima. In 2018, we focused on our partnership with the Locombia Theatre Cultural Association of Andancas (ASCALTA) on the development of the Apuí Project, whose scope is the constitution of two spaces for the shelter and development of cultural projects.

Keywords: VENEZUELAN MIGRATION. PARTICIPATIVE ACTION RESEARCH. MIGRATION ANTHROPOLOGY. SOCIAL MOVEMENTS.

Resumen: Este articulo trae los princípios metodológicos de las acciones de extension junto a la migracion do Instituto de Antropologia de la Universidad Federal de Roraima (UFRR). La metodologia del proyecto tiene su inspiracion em la Investigacion Accion Participatica, traduzida para el português como Pesquisa Ação Participante. El objetivo principal del proyecto era desarollar acciones para acojer, apojar e integrar los migrantes venezuelanos em Roraima (Brasil), tanto refugiados quanto residentes temporários. Trabajamos em la perspectiva de hacer redes de cooperacion entre la universidad, organizações da sociedad civil e voluntários focadas no acojer, apoyo, protection e intregacion de los migrantes em Roraima. Embazamos el proyecto com las sigientes acciones: classes de português para el acojer no Recanto Apuí, Núcleo de Pesquisa em Relações Internacionais de la UFRR e Abrigo del barrio Pintolandia; producion de documentários e investigaciones com el intuito de sensibilizar la opinion publica, subsidiar organizaçiones estatais, organziaciones não-governamentais e estimular la autoorganzicion de los migrantes em Roraima; divulgacion junto a mídia e redes sociales de las acciones del proyecto para informar los interessados e sensibilizar la opinion publica; realizacion de atividades de lúdicas, recreativas e educativas junto a niños, madres e 
padres del Centro de Referência aos Imigrantes do barrio Pintolância; campañas de donacion de alimentos e ropas; orientacion legal a los migrantes na UFRR; participacion em reuniones ampliadas de entidades publicas e privadas que desarollan acciones junto a refugiados em Roraima. Em 2018 nos concentramos em la parceria com la Associação Cultural Locombia Teatro de Andanças (ASCALTA) para la implantacion e manutencion de las casas llamadas Recanto e Comuna que funcionam como vivenda e espacios culturales.

Palabras-clave: MIGRACIÓN VENEZUELANA. INVESGATIÓN ACCIÓN PARTICIPANTE. ANTROPOLOGÍA DE LAS MIGRACIONES. MOVIMIENTOS SOCIALES

Submetido em: 01/12/2018

Aceito em: 28/02/2019

\section{INTRODUÇÃO}

Usualmente, nos países de língua espanhola a pesquisa participante é conhecida como Investigacion Acción Participativa (IAP). Seu precursor mais conhecido nesses países é Orlando Fals Borda, sociólogo colombiano. A IAP tem sido utilizada em áreas muito variadas das ciências. No Brasil, nos remetemos a duas correntes distintas amadurecidas nas décadas de 70 e 80: a Pesquisa Ação, com referências a Michel Thiollent, e a Pesquisa Participante, referendada a Carlos Rodrigues Brandão. Optamos pela junção nominal usual na Venezuela e Colômbia, embora tenhamos mantido o gerúndio usado na nomenclatura portuguesa em vez do particípio no que se refere ao verbo participar. Pesquisa Ação Participante vai ser a nomenclatura que usaremos para nos referir a essa metodologia.

Apresentaremos nossa concepção metodológica na forma de princípios epistemológicos. O corpo é a base de nossa experiência relacional. As relações socioafetivas ocupam um lugar central nos processos de pesquisa ação participante; somos afetados pelos sujeitos pesquisados e pela situação social, política e econômicas nas quais transcorrem nossas pesquisas. Estar presente é a condição básica para esses encontros. Buscamos a transformação social pela autogestão e participação comunitária, potencializando a consciência crítica e a criatividade artística. 


\section{O CORPO É A BASE DE NOSSA EXPERIÊNCIA RELACIONAL}

Nossos corpos são organismos vivos que interagem de forma contínua com o meio ambiente. Quando falamos em meio ambiente, incluímos o mundo imaginário, dimensões desconhecidas e formas de energias imperceptíveis. Estados sólidos, líquidos, gasosos, eletromagnéticos, vibracionais, fotocionais, entre outros, compõem os ambientes do universo no qual vivemos.

Somos uma sequência de fatos vivos. Nos constituímos como microambientes em rede que compõem um organismo. Uma das ações que essa organização espacial permite é a circulação de nutrientes e substâncias. Além de ser um microcosmo para seres microscópicos, como bactérias, permite a mobilidade no campo gravitacional (KELEMAN, p.16, 1992).

O corpo humano se configura nas interações socioambientais. As heranças genéticas e as interações socionaturais geram padrões somaticamente configurados. Os padrões somáticos revelam nosso modo de ser no mundo, fazem parte da inteligência corporal. A configuração corporal é a forma pela qual percebemos o mundo e a nós mesmos. Os limites entre o ambiente interno e externo são tênues e porosos, mas é possível percebê-los quando se trata de corpo físico.

O movimento de dentro para fora e de fora para dentro é uma constante da vida humana, a tal ponto que sua identidade se constitui e se transforma nesse processo de comunicação permanente. Interpretamos o que vivemos segundo nossas representações simbólicas ou esquemas de percepção. Somos seres interativos, uma vez que nos comunicamos com o meio circundante. Este trecho da canção Serra do Luar, de Walter Franco, expressa poeticamente, com muita profundidade, essa condição de interatividade contínua do ser humano:

Viver é afinar um instrumento,

De dentro pra fora, de fora pra dentro.

A toda hora, a todo instante.

De dentro pra fora, de fora pra dentro.

Perceber o próprio corpo é de grande importância no decorrer das relações e processos sociais nos quais estamos envolvidos. O que sentimos se expressa em termos corporais. A consciência refinada do próprio corpo é uma habilidade necessária para fazer extensão e pesquisa junto a imigrantes em situação de vulnerabilidade. Perceber o corpo em-relação-com é estar presente. 
Nosso corpo revela nossa atitude diante da vida. Expressa nossas atitudes diante das relações sociais nas quais estamos inseridos durante nossos trabalhos de extensão e pesquisa. Emoções e imaginação se expressam espontaneamente pela linguagem corporal, na maioria das vezes de forma inconsciente. A palavra é usualmente a forma mais utilizada para revelarmos nossas posturas.

Utilizamos as dinâmicas de trabalho corporal em grupo desde o início do projeto para criarmos um clima de encontro, onde estejamos presentes de corpo e alma, onde sintamos os outros. Nossa intenção era que as reuniões gerais de voluntários, bolsistas, coordenadores de ações e parceiros institucionais fossem momentos de partilha e fortalecimento afetivo.

Com o desmembramento do projeto, seguimos fazendo reuniões gerais com representantes das turmas de português, moradores das casas abrigo, voluntários, agentes culturais da ASCALTA (Associação Cultural Locombia Teatro de Andanças) com fins de tomada de decisões, vivências afetivas e artísticas. O Projeto Apuí é composto por dois espaços integrados e independentes: o Recanto e a Comuna. O primeiro é composto por uma casa abrigo, um salão para reuniões e um chalé para hospedagem de voluntários. Em média, são três famílias abrigadas. No salão, acontecem as aulas de português de acolhimento, oficinas de arte, encontros linguísticos, meditação e massoterapia. A comuna é uma casa de dois andares com sala multiuso, quatro quartos, dois banheiros e varanda. Atualmente está em reforma. Cada casa tem quatro famílias abrigadas.

\section{CENTRALIDADE DAS RELAÇÕES}

Vamos iniciar esse tópico narrando um episódio. Naquela quinta feira quando chegamos no Recanto, eles estavam arrumando as malas e mochilas. Finalmente, depois de alguns meses, estavam de partida para Londrina (PR). Royfill chegara em 2017 a Boa Vista (Roraima, Brasil). Ficou morando com seu cunhado e sua irmã, e por três meses ficou buscando trabalho. Nós o conhecemos nas aulas de português de acolhimento. Otimista, disponível e perseverante, é um homem cuja presença transmitia muita leveza e segurança. Trabalhou três meses na câmara fria de um supermercado. Em dezembro, voltou a Venezuela para buscar a esposa e os dois filhos.

Em março de 2018 chegou a Boa Vista (RR) com sua família. Ficaram morando na casa da irmã. Porém, o apartamento era pequeno para duas famílias. 
Jaqueline, sua esposa, é engenheira industrial. O diploma não revalidado foi um impedimento para conseguir trabalho na sua área profissional. As crianças, Raziela, 9 anos, e Andreas, 7 anos, conseguiram vaga em uma escola municipal..

Decidiram buscar outro lugar do Brasil para viver. Os primeiros contatos foram com o atendimento da Organização Internacional da Migração (OIM) e com o Serviço de Apoio aos Migrantes dos Jesuítas (SPMJ). Em sua busca, escolheram Curitiba (Paraná, Brasil) como destino, entrando, assim, em um grupo de Whatsapp administrado por um venezuelano que está em Curitiba.

Através desse grupo, eles fizeram contato com o Pastor Kalvin Cantidio, em Londrina (Paraná, Brasil), muito sensível a causa migratória. Ele próprio e sua esposa foram migrantes na Itália, onde se converteram a Calvary Temple. Ele pastoreia a Igreja do Calvário em Londrina, e apresentou a proposta de receber a família no conselho da igreja. Aprovada a proposta, conseguiram a cessão de uma casa no Jardim São Fernando, próximo a igreja, para hospedar a família por nove meses. Quando fui a Londrina visitá-lo no final de outubro de 2018, ele me apresentou o centro de formação da igreja e a casa disponibilizada para a família. Uma igreja jovial e envolvida nas questões sociais, a ponto de participarem de reuniões da rede de atendimento do CRAS 8 (Centro de Referência da Assistência Social) .

Resolvida a questão da recepção e moradia, ficou em aberto o translado. A OIM tem um programa voltado para reunificação familiar, porém, Royfill e Jaqueline não se enquadravam nesse programa. Havia outro programa no Ministério do Desenvolvimento Social que poderia pagar as passagens aéreas para Londrina.

O Alceu, agente da OIM/Roraima, conversou com sua chefe. Esta entrou em contato com o Pastor Kalvin e passou o caso para a casa civil da presidência da República, que contatou o responsável pelo Programa no Ministério do Desenvolvimento Social em Brasília (Distrito Federal, Brasil). Estes designaram uma pessoa em Londrina para fazer a vistoria da casa e dos receptores. Kalvin conta que foram várias ligações de pessoas ligadas a instituições e órgãos variados, até que fizeram a vistoria e foi aprovada o repasse de verba para o pagamento das passagens. Esse processo durou cerca de dois meses.

Naquela quinta feira, em novembro de 2018, as famílias que moravam no Recanto tomaram seu café da manhã juntos sentados na grande mesa de cedro. Rotina comum na casa. A mesa foi uma doação de uma benfeitora brasileira que vive em Nova York (EUA). 
Evelina, indígena da Etnia Tuiuka, grávida de 7 meses. A filha Ayandará deve nascer em dezembro. Pedro, Fabíola e as duas crianças, família de refugiados venezuelanos, aguardam passagens aéreas para se mudarem para o Paraná. Nervic e as duas filhas se preparam para irem ao encontro da sua irmã gêmea Neurik em Juiz de Fora (Minas Gerais, Brasil). Esta última família está sendo apoiada pela Pastoral do Migrante da Igreja Católica.

Durante a tarde, Royfil e Jaqueline tinham reunião com a equipe da OIM. $\mathrm{Na}$ reunião, foram comunicados que talvez viajassem naquele dia. Confirmado. Quando passamos em torno das 20 horas, estavam terminando de arrumar as malas. Fora do quarto o clima era de despedida. Lágrimas. As crianças brincavam e pareciam não sentir a dor da partida. Já os adultos viviam intensamente aquela sensação de encerramento, um momento único em sua beleza. Compartilhamos alguns pãezinhos recheados com omelete para tomar suco de caju e café com leite. Abraços. Como os abraços verdadeiros são intensos! A intensidade emocional venezuelana em toda a sua força. Era 6h26 da manhã quando Royfill enviou uma foto, via Whatsapp. Estavam fazendo a conexão no aeroporto de Brasília. Às 13 h30 estavam em Londrina.

Como se pode ver, a rede institucional composta por órgãos governamentais, igrejas, agências da ONU e ONGs é um fator importante para viabilizar o acolhimento das famílias. Entretanto, o campo relacional, cujo eixo gira em torno dos vínculos afetivos criados entre as pessoas diretamente envolvidas no processo, constitui a beleza dos acontecimentos.

O abrigamento, o translado para outras regiões do país e o apoio alimentar são ações emergenciais necessárias, porém a centralidade do nosso trabalho está na construção de vínculos relacionais. Isso nos permite ir além da frieza dos atos administrativos. Recantos de beleza e resistência emergem nas relações humanas como um processo criativo e proativo. Supõe disponibilidade e intencionalidade. Nessa perspectiva, o suporte para a ação em rede está no campo sócio-afetivo-corporal.

Há situações que nos afetam profundamente que nos mostram situações complexas em nós e nos outros com os quais estamos atuando. É importante identificar os sentimentos que nos atravessam frente ao acolhimento e a violência. Um clown venezuelano que faz performances em semáforos relata que um motorista, ao ser abordado por uma indígena warao pedinte, abaixa o vidro, saca um vasilha com pedaços de gelo e lança sobre ela; um estudante relata um episódio semelhante, em que um senhor migrante que vende laranjas 
no semáforo é escorraçado aos berros por um motorista que lhe ordenava que voltasse para seu país; crianças, jovens e adultos expostos ao sol e a poluição em situação de mendicância. Trabalhadores recebendo diárias de vinte reais; mulheres vivendo em cárcere privado em prostíbulos. São fatos que nos tocam e apelam para reverter esse quadro social.

Muitas vezes nos sentimos impotentes tocados pela tristeza e indignação. Os discursos políticos antimigração na campanha eleitoral de 2018 intensificaram a xenofobia. Por isso, nós necessitamos de espaços onde possamos nos expressar, conversar e trabalhar de forma lúdica e corporal os nossos medos, angústias e raivas frente as situações de violência que nos afetam.

Nesse sentido, as danças circulares, a capoeira, a ioga e os banhos de rio têm sido momentos de beleza onde podemos trabalhar nossos sentimentos. Necessitamos estar atentos a nossos impulsos de violência para evitar projetá-los sobre os demais, tampouco reproduzi-los nos momentos em que estamos trabalhando com os migrantes. Há também as tensões e conflitos entre membros da equipe, e entre participantes das atividades.

As situações cotidianas de pesquisa e de extensão expõem pressupostos e conceitos que fomos construindo durante nossa vida, durante nossa carreira profissional, durante nossa atuação em projetos sociais. Trazemos uma visão de mundo, trazemos uma série de experiências e posturas. Quando nos encontramos em espaços compartilhados com o outro, tendemos a realizar uma operação de enquadramento. O oposto também é válido. Os sujeitos sociais com quem trabalhamos também tendem a emitir juízos sobre nós a partir de conceitos já construídos.

Por exemplo, quando vamos ao encontro das prostitutas da região do Passarão (Boa Vista - RR) em situação de rua, nos distinguimos dos clientes e das profissionais do sexo. Os clientes que abordam as prostitutas e os grupos que conversam conosco, quando informados que somos da universidade, nos enquadram dentro de um quadro de expectativas do que seja uma universidade. Bem como, nos vemos envolvidos num redemoinho de sensações e pensamentos em relação a situação que estamos testemunhando.

Segundo Alejandra Cedeño (2012, p.16), a troca construtiva deve ser nosso guia na construção de redes horizontais no cotidiano nas pesquisas junto a grupos vulneráveis e contra hegemônicos, seja no âmbito das políticas públicas, sejam no âmbito do terceiro setor. Coaduna com Peter Spink (2008), que recomenda o fortalecimento de iniciativas potencializadoras que existam no lugar. 
Podemos ajudar sem atrapalhar quando conversamos com as pessoas de forma compreensível, traduzindo os vocábulos técnicos das diferentes profissões e políticas públicas, para que, tendo acesso a eles, possam ter mais clareza ao tomar as decisões. Podemos também usar nossa posição de intelectuais reconhecidos para mediar conversações entre grupos populares de migrantes e os órgãos governamentais ou empresariais.

O processo de pesquisa e extensão participante é relacional, e implica em inserção e familiarização, aqui entendidas como esse conhecimento mútuo decorrente da confiança que vai se criando a medida em que convivemos. Envolve compromissos e emotividade. Buscamos a superação da distância tradicional entre sujeito-pesquisador e sujeito-pesquisado.

A inserção implica em relações pessoais e em objetivos comuns com grupos e organizações locais. Implica num engajamento integral (intelectual, emocional e físico), porém se resguarda a cientificidade na elaboração e análise dos dados, bem como, na construção do referencial teórico. Implica também num envolvimento com aqueles que estão sendo investigados, e exige um comprometimento entre o pesquisador e os pesquisados (BRANDÃO, 1985, p. 8).

Podemos apresentar alguns eixos orientadores do pesquisador-extensionista nesse processo: compartir com pessoas reais momentos redutores de distância do outro no interior do seu cotidiano; essa relação apaixonada e apaixonadamente é um estado afetivo que envolve "fé" nas pessoas, confiança, empatia; uma relação permeada de frustrações, decepções, raivas e desânimos.

A turma de Organizações Internacionais realizou intervenções no Centro de Referência aos Imigrantes nas quintas feiras de manhã. Quando convidam os abrigados para a aula de português, os indígenas se adiantam e ocupam praticamente todos os lugares. Os criollos, venezuelanos não-indígenas que eram minoria no alojamento, ficam de fora da aula.

Durante a aula, alguns que conhecem mais tentam impor seu ritmo, tentando monopolizar a atenção dos educadores. O conflito de interesses é real, e a mediação dos estudantes, crucia Mesmo que nunca tenham passado por situação semelhante, seu papel, naquele momento, exige posturas. É desafiador.

Na manhã do ano novo, a equipe da Fraternidade Internacional, ONG humanitária que gerenciava o CRI (Centro de Referência aos Imigrantes)/ Pintolândia, se deparou com um abrigo com lixo espalhado por todo o espaço, com quase todos os adultos caídos pelo chão após um alto consumo de álcool. Desalentados, entram na viatura e voltam para casa. Retornam no dia 
seguinte e após avaliação com as lideranças dos abrigados, se retoma a rotina pactuada. Mas o estado de choque que eles vivenciaram naquele dia provocou sentimentos de exasperação muito fortes nos ativistas.

A militarização impôs disciplina militar nos abrigos para refugiados. Os projetos educativos e assistenciais passaram a ser realizados via convênios com organizações não-governamentais de grande porte. Monitores, professores e estagiários foram contratados. O caráter improvisado e espontâneo do atendimento a migração em 2017 foi substituído por um sistema institucionalizado comandado pelo exército, onde as agências da ONU e organizações não-governamentais assumiram papéis complementares na lógica da Operação Acolhida.

Ações independentes ligadas a organizações religiosas e culturais se expandiram. É o caso do Serviço de Apoio aos Migrantes dos Jesuítas e do Projeto de Apoio aos Migrantes em Roraima / INAN/ UFRR, no campo da sociedade civil autônoma, em especial, nas duas casas abrigo do Projeto Apuí: o Recanto e a Comuna.

\section{ESTAR PRESENTE É A CONDIÇÃO BÁSICA PARA ESSES ENCONTROS}

A pesquisa-extensão participante é um encontro. $\mathrm{O}$ que supõe estarmos disponíveis para perceber o outro para além das palavras. É olhar, é tocar, é observar, é interagir, é expor-se, é estar no aqui e agora. E os pressupostos: princípios, teorias, conceitos, valores, técnicas de observação e intervenção? Trazemos para o aqui e agora da ação que estamos envolvidos, admitindo que sejam colocadas em cheque. Quando necessário, nos permitimos abrir mão ou alterar nossos planejamentos. A situação concreta nos guiará. Podemos denominar isso de intenções flexíveis

O direito ao bem estar e a beleza, a construção de vínculos afetivos e de espaços de diálogo compõe o horizonte utópico do campo relacional no qual nos movemos. Em todo caso, é importante conhecer as organizações com as quais estamos trabalhando, inclusive identificando as relações internas de poder.

Vamos citar um exercício de percepção para estimular o estar presente. Fechamos os olhos e quando os abrimos movimentamos nosso olhar sobre o campo visual a nossa frente, acompanhando o contorno das imagens. Sem se preocupar se estamos vendo com clareza ou com o que estamos vendo. 
Apenas deixamos o olhar correr livre e contínuo. Se trata de deixar as pessoas e situações se manifestarem, um exercício simples de redução dos conceitos prévios que trazemos, inclusive dos quadros teóricos com os quais analisamos e nos pomos nas pesquisas sociais.

A escuta sensível proposta por René Barbier se orienta nessa mesma direção. Essa postura se aproxima da poiesis da fenomenologia e da não-ação do taoísmo. É um momento de observação e disponibilidade. A medida que vamos nos relacionando mediado pelas ações culturais que acompanhamos ou desenvolvemos, vamos construindo laços e formando imagens uns dos outros. A medida que vamos nos deparando com desafios macrossociais presentes no cotidiano dos grupos, vamos delineando quadros teóricos. Se permanecemos atentos ao movimento da vida no cotidiano, estaremos sempre reelaborando esses quadros de referência.

A pesquisa participativa acadêmica tem enfrentado dificuldades para combinar linguagem e tempo acadêmicos com os tempos das comunidades. Fazer slow sciense quando a demanda acadêmica de um curso integral permite apenas frequentar a comunidade uma vez por semana por um período de quatro horas, é difícil.

Nosso projeto se desenvolve fora da universidade, por isso temos encontrado dificuldade de encontrar estudantes com disponibilidade de tempo, pois os cursos têm um grau de exigência bastante elevado. Inclusive os bolsistas do Programa Pró-Acadêmico só podem fazer suas atividades dentro dos campi da Universidade Federal de Roraima.

Nossa intencionalidade orienta nosso campo de ação. É um deixar-se levar intervindo ao mesmo tempo. Cada atividade ou ação específica que vá surgindo nesse movimentar-se coletivo comporá está grande sinfonia improvisada. Nesse campo se manifestará o que nos habita e atravessa: alegrias, paixões, medos, esperanças, lamentos e dores. Os grandes temas perenes e pontuais presentes em nossa sociedade se manifestarão, mas as formas como serão abordados ou digeridos nos momentos coletivos dependerá de cada situação.

O campo intencional é também um campo espaço-temporal, ou seja, nossos momentos de criação, sejam artísticos ou intelectuais, religiosos ou terapêuticos, ocorrem num espaço delimitado, seja físico ou virtual. Seja metafísico ou frequencial, seja emocional ou ideológico. O campo é mais amplo que o lugar, pois este está vinculado a territorialidade. Se apropriar de um território e transformá-lo é interessante, mas é importante lembrar que existem 
outras dimensões no aqui e agora que se mesclam com a dimensão material dos lugares nos quais vivemos.

A documentação e o registro dos fatos vividos durante o processo de pesquisa-extensão é um procedimento usual nas pesquisas sociais de cunho qualitativo. Nessa proposta, é um exercício de presença relacional. A formação de um banco de dados com esses materiais fazem parte do processo. Serão a base para análise relacional, vestígios presentes dos ocorridos. Elementos para o exercício ficcional da elaboração de representações relacionais. Nossa experiência tem mostrado que a organização dos registros feitos imediatamente após as ações executadas guardam maior riqueza de detalhes. Anotações em forma de narrativa; ordenamento de fotos e vídeos. Porém, muitos insights vêm a posteriori.

A transformação desses materiais em um acervo público de informações ou aberto aos membros e apoiadores dos projetos deve ser encaminhada com cuidado. Imagens e fatos que envolvam situações constrangedoras ou privadas nem sempre podem ser expostas sem autorização dos envolvidos. As estratégias de caráter participativo para definir que informações serão apresentadas e para quem dependerá das condições reais de cada projeto de pesquisa.

\section{COMUNIDADE E AUTOGESTÃO}

Comunidade aqui é um estado de sinergia que se estabelece num grupo de seres humanos. Nesse estado, formamos uma comum-unidade que cria ou se apropria do espaço onde está situada. Esse estado de unidade pode se dar no ciberespaço, no imaginário compartilhado ou no território, tipo casa, centro cultural, rua, bairro ou região. Esse espaço de compartilhamento é também um espaço de decisões, de trocas e criações.

Uma comunidade pode ser permanente, tendo uma rotina, espaços de reunião contínuos, objetivos, ritos e linguagem comum. Mas também pode ser volátil e fugaz. Pode se formar pontualmente e se desfazer, como também pode se articular em rede com parceiros, institucionais ou informais. Por isso, podemos falar de comunidades territoriais baseadas em terras indígenas, por exemplo, mas também de comunidades terapêuticas, comunidades temáticas, comunidades virtuais.

Pode ter apoio de pessoas, profissionais do serviço público, universitários, amigos, simpatizantes, governo, empresas ou igrejas. Porém, quando se busca a autogestão, o poder de decidir de forma singular e coletiva os caminhos de 
sua vida repousa em seus membros. Os critérios para definir quem é membro (insiders) e quem é externo (outsiders) à comunidade pode variar de acordo com as situações. Por exemplo, participam das reuniões semanais da Comuna as famílias que moram na casa, os dirigentes da Associação Lo Combia Teatro de Andanças (ASCALTA), representantes do Projeto a Apoio aos Refugiados da UFRR e agentes culturais voluntários. A Comuna é uma casa abrigo situada no bairro união em Boa Vista (Roraima, Brasil) cedida em comodato a organização não-governamental ASCALTA.

Se sentir parte de uma comunidade produz um sentimento de pertencimento e responsabilidade pelo lugar e pelas ações coletivas. Responsabilidade no sentido de responder-por. Os moradores do Recanto e da Comuna e os agentes culturais que atuam nesses espaços têm as chaves das salas multiuso e organizam a agenda de uso desses espaços. Isso também pode ocorrer nos projetos acadêmicos que tem sala própria nas universidades, o coordenador e os estudantes que têm livre acesso e sendo os responsáveis pela gestão desses espaços.

Uma característica das organizações autogestionárias é a busca da gestão coletiva das ações e do espaço baseada em relações horizontais. Isto implica na relativização das diferenças funcionais, salariais, acadêmicas, etárias, sexuais ou étnico-raciais entre os que pertencem aquela coletividade.

As diferenças são reconhecidas e mantidas, mas a possibilidade de participar das decisões está ao alcance de todos os membros. Delegar poderes a alguém para tomar decisões ou criar momentos de decisão consensual são estratégias viáveis, desde que haja comunhão emocional.

Nossa experiência no acolhimento e apoio a migrantes tem nos revelado que o controle dos recursos financeiros para manutenção das casas e das atividades culturais impõe uma hierarquia baseada no poder econômico. Criar relações de poder horizontais tem sido um grande desafio. O mesmo se dá nas aulas de português, onde os grupos chegam com os papéis introjetados de aluno e professor baseados na educação tradicional, o que exige enorme esforço dos educadores para transformarem tal concepção nas relações educativas. Temos concebido as atividades de aprendizagem linguísticas como encontros socioafetivos.

A autogestão leva em conta as leis do mercado, o controle do estado e a opinião pública, mas como elementos que compõem o cenário do sistema de controle centralizado nas instituições de poder, mas não como ditames aos quais temos que nos balizar. Reconhecendo que elas estão internalizadas em nós, relativizamos o poder do estado e do mercado. 
A participação massiva no campo dos direitos sociais tem se mantido presente no cenário mundial. A participação em mobilizações massivas e a participação em conselhos para definição de políticas públicas aparecem como um espaço de trabalho em rede para grupos autogestionários. Articular práticas socioculturais em rede tem sido uma alternativa interessante para tirar os grupos do isolamento.

\section{A TRANSFORMAÇÃO SOCIAL COMO META}

Fazemos pesquisa-extensão engajadas que fomentam a emancipação social. Pesquisas sociais mescladas com apoio e atuação, confiança, proximidade, envolvimento e compromisso fazem parte do processo.

Para Alejandra Astrid (2006), a emancipação tem a ver com a ocupação de espaços de possibilidades. Como potência e resistência que é cotidiana e fractal. Seu alcance e intensidade na contraposição aos sistemas de controle baseados na força bruta e introjeções sutis são irregulares e dinâmicas.

Sentados em bancos improvisados em frente a comuna, conversávamos sobre a vida, enquanto as crianças brincavam sobre o monte de areia lavada. O sol se punha e alguém nos trouxe um café temperado com sorrisos. Todos os dias surgem milhares de pequenos e grandes espaços de resistência e criação. E quando se acabam, mudam de forma ou se manifestam de outras maneiras. Lembrar disso é importante, principalmente em momentos de avanço das forças conservadoras e autoritárias na política do Brasil e Venezuela (CEDEÑO, 2012, p 45).

A transformação social supõe o aprofundamento da análise crítica do cenário macrossocial. Compreender as estruturas políticas e econômicas geradas pelo capitalismo especulativo contemporâneo, a partir da percepção do sofrimento no cotidiano das pessoas, bem como perceber os padrões de distinção de idade, raça, etnia, religião, classe social, gênero, entre outros, que condicionam nossa percepção e nosso comportamento no correr de ações nos projetos.

Quando falamos em resistência, estamos pensando nas ações coletivas voltadas para resistir a expansão e aprofundamento das desigualdades sociais e processos de homogeneização cultural nas sociedades capitalistas contemporâneas. Houve uma expansão das políticas públicas de inclusão na América Latina, em especial, Brasil e Venezuela nas últimas décadas, porém estamos 
assistindo nos últimos anos um retrocesso capitaneado pelas forças elitistas e conservadoras em vários países da Europa e América Latina.

É importante observar que as forças sociais ligadas ao narcotráfico, latrocínio, tráfico humano e extorsão têm se organizado de forma empresarial e política e seu modus operandi cotidiano tem se caracterizado pela intimidação, agressão e imposição de suas vontades pela força das armas.

Ou seja, as forças reacionárias baseadas no ódio justificam sua forma de agir na violência da criminalidade organizada. Por outro lado, a pilantragem se apresenta como uma geração bélica suicida, onde matar ou morrer faz parte natural do cenário existencial. As grandes corporações no âmbito do mercado globalizado e os estados nacionais no âmbito da política são as agências de controle social que dirigem as macroestruturas sociais a nível mundial.

Queremos gerar uma proposta teórico-metodológica que busque estudar e potencializar formas de resistência e criação que fortaleçam subjetividades rebeldes, que sejam sensíveis ao horror e que questionem a cotidianidade capitalista nos mercados lícitos e ilícitos.

A transformação das relações sociais em vista a uma convivência humana onde haja bem estar e respeito ao conjunto de seres que interagem conosco, se nos apresenta como constituído por muitas microtransformações cotidianas no pessoal e no coletivo. Em muitos lugares, simultaneamente, se vai tecendo esta rede de iniciativas transformadoras com enfoque libertário e autocrítico. $\mathrm{O}$ acolhimento tem se feito muito presente no deslocamento massivo de migrantes venezuelanos, nem sempre amplificado pela mídia ou redes sociais. Este é um mundo de sombras e luzes, rejeição e acolhimento.

\section{POTENCIANDO A BELEZA}

Vamos nos remeter a filosofia aristotélica para refletir sobre as potencialidades. Segundo essa corrente de pensamento, o ser se manifesta enquanto ato e potência. Os seres tem em si a capacidade de se tornarem algo, de manifestarem qualidades, de agirem.

Entretanto, essa potencialidade depende de intenções e condições que as transformem em ato. As sementes são os exemplos palpáveis dessa alquimia. Quando plantadas em solo fértil e tendo as condições favoráveis, germinam e se tornam plantas. Podemos olhar a potência como estado de inércia. Os elementos que podem detonar, provocar ou impelir a saída do estado de 
potência-inerte para a ação variam de acordo com as estruturas e conjunturas socioambientais.

Potencialidades se constroem nas relações socioambientais, bem como sua manifestação. Podemos assumir valores voltados a construção da emancipação social. Aliás, normalmente, a visão crítica é acompanhada de indignação em relação às estruturas opressivas e seus agentes.

A elaboração coletiva dessa visão crítica de mundo é, em si, uma ação no âmbito da racionalidade. $\mid \mathrm{O}$ âmbito das ideias pode levar a ações práticas. Elas potencializam ações culturais, seja no âmbito político, econômico, religioso ou artístico. Também podem potencializar habilidades, competência e aptidões em nível pessoal e grupal.

Tomar consciência é despertar potencialidades. Nesse sentido, o conceito-utopia conscientização, tão difundida nos anos 80 pela educação popular, ganha novo sentido quando relacionada a pequenos atos do dia-a-dia, quando nos damos conta de como nos movemos e onde nos bloqueamos, relacionando nossas posturas com nossa vida. Dessa forma, podemos ver onde se alojam nossos medos, dúvidas, dificuldades, alegrias e potencialidades. Unindo razão, afetividade, corpo e desejo (CEDEÑO, 2012, 43).

A arte e o esporte produzem diversas formas de potencialização. É difícil quando esta potencialização vem de atividades ilícitas como o narcotráfico ou enfrentamento com a polícia. Porém, num mundo tão desigual como este não podemos negar que essas são formas relativamente rápidas e efetivas, ainda que tenebrosas, de alcançar visibilidade e sentir-se importante, ainda que implique em viver pouco. Assim diríamos com Spinoza que nada mata uma paixão, salvo uma paixão mais forte e que por isso é necessário que sejam construídas atividades emocionantes para os jovens que possam competir com a adrenalina do crime. A ativista transexual Melissa Campus argumenta: Graças a violência aprendi a defender-me; ao defender-me aprendi a lutar por meus direitos e lutando por meus direitos descobri qual era meu lugar no mundo (CEDEÑO, 2012, 16).

Potencialidades tem a ver com possibilidades de ação. Nossos encontros podem nos afetar de tal forma que torne ato mis em scène a alegria e criatividade. Todavia, há encontros que desestruturam nosso corpo e nos abalam profundamente, potencializam o sofrimento, mas que podem se mostrar como espaços de crescimento e diluição de fantasmas de grupos e comunidades. Enfim, apoiar iniciativas potencializadoras da beleza, alegria e justiça em lugares marcados por diversos tipos de violência faz parte de nossas intenções estratégicas. 
Gostaria de agregar nessa reflexão os princípios vitais da ciência Ayrvédico de Pitta, Vatta e Caffa. Os três conceitos se referem ao processo de estabilidade e instabilidade; permanência e mutação; repouso e agitação. A potenciação tem a ver com o despertar de capacidades que estão em repouso. Esse despertar pode vir de estímulos ambientais externos ou internos.

Nesse sentido, a estabilidade ou permanência podem ser representadas nas estruturas sociais mais duradouras que condicionam as relações sociais. Os elementos potencializadores do processo criativo vêm das provocações. As potencialidades podem explodir quando estimuladas, gerando movimentos socioculturais. Quando as intenções chegam ao nível da consciência social, podem gerar ações e transformar a realidade. O inverso também é válido, quando a potência vira ato, pode gerar novas consciências.

A inércia tomou contato do grupo que habitava na comuna. Viageiros artesãos, herdeiros da cultura hyppie dos anos 60. Já haviam se passado quatro anos (2014-2018). Diante da necessidade de abrigar famílias de migrantes, iniciamos uma reforma na casa, o que implicou em solicitar que os moradores antigos se retirassem. A injeção de capital, combinado com o trabalho em mutirão dos novos moradores, reinventou a casa num novo formato e numa nova dinâmica. A velha estrutura sofreu transformações e se renovou potencializada pela utopia do apoio mútuo na construção de um espaço autônomo.

A beleza é uma projeção de nossos desejos e uma qualidade potencial dos seres. Pode ser encontrada inclusive na tristeza, na dor ou no sofrimento. Nós priorizamos a produção da beleza ligada a alegria, leveza e comunhão. Não se trata de gerar um mundo fantasioso que ignora as opressões da sociedade onde vivemos. Se trata de potencializar dimensões do bem viver que estão latentes, porém reprimidas ou esquecidas. Partamos da constatação que experimentamos a beleza na forma de sensações, emoções, ritmos pulsáteis e sentimentos.

As linguagens artísticas nos permitem acessar e produzir o belo, seja apreciando, seja criando. Abordam e expressam de forma metaforizada a dimensão poética da vida. A arte, em sua dimensão poética, deve ser capaz de converter o sofrimento em valor estético e propiciar a experiência do gozo estético.

Iniciamos a aula de português de acolhimento com a canção Anunciação, de Alceu Valença. Leitura, palavras desconhecidas, exercícios vocais, movimentação corporal. Ao final, o grupo canta alegremente, solta sua voz, encontra harmonia. Em seguida, conversamos sobre as paixões. Aparecem relatos deslumbrantes. Por fim, pedimos para escrever uma frase em espanhol sobre as 
paixões humanas e depois pedimos para traduzir a frase para o português com ajuda dos colegas. Segue uma história criada por um migrante sobre a temática:

O pequeno gato saiu de casa e se perdeu na floresta. Caiu numa cova escura. Desesperado pede socorro. Um macaco, ouvindo os miados desesperados se aproxima. O gatinho pede que o ajude. $\mathrm{O}$ macaco responde que para sair da caverna ele deve responder a um enigma: o que move as pessoas? A paixão ou a razão?

O contato com a beleza e, melhor ainda, a produção da beleza e alegria em nossas vidas, nos ajuda a dizer sim a vida e não aos horrores. Gerar beleza é gerar bem viver. O direito a beleza é também exercer a indignação de forma bela.

Criar espaços de conversação e de manifestações artísticas, espaços de amizade, de ação conjunta e luta coletiva por melhores condições de vida. Espaços de celebração das conquistas e derrotas diárias. Construir alguns recantos de beleza dentro do mundo onde vivemos (LEON CEDEÑO, 2012, 62).

As discussões sobre a produção artística que opera com práticas interativas que acontecem no tecido social, mimetizando ações corriqueiras da vida e repercutindo no modo como as pessoas convivem e se organizam cotidianamente, vêm ocupando espaços significativos nos movimentos artísticos contemporâneos (SEQUEIRA, 2010, 10).

Essas práticas de arte põem em questão, entre outros temas, o potencial da arte para transformar o espaço social e as relações humanas. Gostaria de apresentar o depoimento de Alexandre Sequeira, fotógrafo e docente da Universidade do Pará, sobre essa perspectiva de arte no cotidiano comunitário:

Minhas últimas pesquisas lidam com a aproximação e interação com indivíduos ou grupos, promovendo, a partir da confiança e parceria que se estabelecem a partir desses encontros, dinâmicas espontâneas de manipulação criativa do cotidiano, como mecanismos de construção de relações de alteridade social. (SEQUEIRA, 2010, 11)

Se trata de uma produção artística fundamentada no alcance e na participação do outro. Os modos de contato e de invenção de relações, bem como os registros documentais desses processos, pensam a vida como arte. Trata-se de uma nova configuração do fazer artístico, onde a hermenêutica passa a englobar a experiência estética, intitulada por Nicolas Bourriaud de estética relacional (SEQUEIRA, 2010, 60).

Cria-se um espaço/momento de relações orientados pela presença, troca construtiva, potencialização da criatividade e da visão crítica. Aqui o 
processo de encontros é o foco principal, sendo a criação artística um resultado natural do processo.

As aspirações da filosofia crítica tradicional da Escola de Frankfurt em relação a função crítica e transformadora da arte passam a operar na condição de micro-utopias. Há uma busca por propiciar espaços nos quais cada um possa expressar seus pontos de vista e experimentar suas escolhas em um mundo cada vez menos participativo.

A relação dos grupos com os materiais ou insumos utilizados nas obras é outra questão. Avaliando a recomendação budista de respeito a todos os seres, sentimos que os recursos que usamos têm vida social e devem ser tratados com reverência. Estamos propondo uma visão que vá para além do conceito de recursos sustentáveis.

Por fim, pensemos um pouco sobre os critérios de definição do que seja bonito. Esses critérios, baseados em padrões culturalmente aceitos sobre beleza, estabelecem uma hierarquia que vai do bonito ao horroroso. Nos é vedado se eximir de utilizá-los. Mas é possível repensá-los e trazê-los a consciência pela experimentação de novos padrões estéticos.

Nesse sentido, as ações artístico-comunitárias são laboratórios. Isso vale também para trabalhos na área da saúde e qualificação técnica. O olhar externo será um dos condicionantes dessa revisão. Muitos alters serão levados em conta na construção da escala que valia os graus de beleza dos produtos artísticos criados. Por outro lado, será as vivências emotivo-corporais coletivas a principal fonte para a consolidação dos critérios de percepção da beleza, pois o ingresso num estado de sinergia compartilhado onde o belo é experimentado sensorialmente como êxtase, sustentará as posturas, os postulados e a criatividade em relação ao belo.

\section{COMENTÁRIOS CONCLUSIVOS}

Uma ciência compreensiva que combinar análise crítica do macrossocial com imersão no microssocial. Usamos as análises de macroestrutura sociais para ajudar a compreender o local, o cotidiano, mas longe de efetuar um enquadramento interpretativo rígido. Quando recorremos a busca de informações sobre contextos culturais com os quais estamos trabalhando, é para enriquecer nosso olhar e não para estreitá-lo. As culturas se referem a 
estruturas simbólicas produzidas e reproduzidas socialmente, elas existem em pessoas corporificadas, materialidades e virtualidades. São estruturas dinâmicas, não pairam sobre os indivíduos como se tivessem vida própria.

Macro e micro são referenciais que nós inventamos para nos localizarmos. Inexistem em si, pois existem num todo em movimento. A relação entre o micro e o macro é de mútua constituição.

Assumimos a institucionalidade moderna da produção de saber científico, relativizando-a. O paradigma antropocêntrico, a racionalidade lógica experimental-analítica, a utilização de um arcabouço teórico baseado em conceitos precisos e coesos, a especialização, são postulados presentes em nossas pesquisas. Trazemos também a metáfora, a poética e a metafísica. Abrimos espaços para a intuição, para o lúdico e para o emocional. Continuamos fazendo registro de dados, sistematização e análise.

As teorias críticas que nos permitem desvendar as estruturas injustas de poder em tempos de globalização são ferramentas importantes para desmascarar as ideologias camufladoras e reprodutoras dos sistemas de opressão. Cremos que a consciência crítica é potencializadora de ações transformadoras das estruturas opressivas, sejam elas de gênero, étnico-raciais, econômicas ou religiosas.

Como já afirmamos anteriormente, as teorias devem ter seu uso mitigado na interpretação das relações cotidianas. A imersão no microssocial supõe um despojamento de conceitos prévios que possam nos impedir de encontrar as pessoas organizadas coletivamente em sua plenitude. No mínimo, temos que atenuar os efeitos de enquadramento explicativo que muitas dessas teorias trazem embutidos nas suas práticas de pesquisa.

Vislumbrarmos a superação da fragmentação do conhecimento científico é fundamental. As fronteiras entre psicologia social, antropologia, sociologia, ciências políticas, economia, pedagogia e filosofia social são tênues ou inexistentes. São ciências sociais. Por isso é importante compor equipes interdisciplinares e transitar por várias áreas do conhecimento.

Os paradigmas que temos utilizado para pensar as relações sociais são insuficientes para abordar essa realidade social micro-macro-cósmica em movimento continuo, e o desenvolvimento de um paradigma ecocêntrico que dê conta da complexidade das relações parece ser uma demanda premente. 


\section{REFERÊNCIAS}

CEDEÑO, Alejandra Astrid Leon. Psicologia Comunitaria del cotidiano - arte y acción Psicosocial em Londrina (Brasil). Searbruckin (Alemanha), Editorial Academica Española, 2012.

KELEMAN, Stanley. Anatomia Emocional. São Paulo, Summus, 1992.

SEQUEIRA, Alexandre Romariz. Entre a Lapinhada Serra e o Mata Capim. Belo Horizonte, Universidade Federal de Minas - Escola de Belas Artes, 2010.

SPINK, Peter O pesquisador conversador no cotidiano (2008). Revista Psicologia e sociedade,20 (1) Apud CEDEÑO, Alejandra Astrid Leon. Psicologia Comunitaria de lo cotidiano - arte y acción Psicosocial em Londrina (Brasil).

VIVEIROS DE CASTRO, Eduardo. O Nativo relativo. Rio de Janeiro, Mana vol.8 Apr.2002, ISSN 16784944, http://dx.doi.org/10.1590/S0104-93132002000100005 acessado em 22/04/2016. 